\title{
Minimally invasive physiological correlates of social behaviour in belugas (Delphinapterus leucas) under human care
}

\author{
Justin T. Richard, ${ }^{1,2}$ Rachael Levine,, ${ }^{1,2}$ Tracy A. Romano² \& Becky L. Sartini ${ }^{1}$ \\ 'Department of Fisheries, Animal and Veterinary Sciences, University of Rhode Island, Kingston, RI, USA; \\ ${ }^{2}$ Mystic Aquarium, Mystic, CT, USA
}

\begin{abstract}
Simultaneous observations of reproductive physiology and behaviour were conducted on a group of two male and two female belugas under professionally managed care for one year to explore potential mating strategies. Weekly blow sampling for progesterone in females was used to define the breeding season by detecting three oestrous cycles in one female. Twice weekly blow sampling for testosterone and twice monthly testes measurements via ultrasonography were used to detect reproductive seasonality in both males. Female-male association frequency varied longitudinally, with $70 \%$ of all interactions occurring during the 16-week breeding season. Male-male associations did not vary seasonally. Male display behaviours towards the female occurred 14.8 times more frequently during the breeding season $(0.164 \pm 0.188$ behaviours $/ \mathrm{min})$ than outside of the breeding season $(0.011 \pm 0.042$ behaviours $/ \mathrm{min})$. The cycling female responded variably to male display behaviours by altering swim speed or body orientation towards the male. Although this small sample size limits broad conclusions, the frequent display behaviours, low copulation rate and lack of serious male-male aggression are consistent with predictions for pre-copulatory female mate choice developed from the current knowledge of beluga reproductive physiology. These observations, which are not feasible for wild belugas, provide important management considerations because reduced opportunities for mate choice could limit the reproductive rate, especially in small populations.
\end{abstract}

\section{Keywords}

Reproduction; cetacean; mating strategies: blow; steroid hormones; aquarium

\section{Correspondence}

Justin T. Richard, 9 East Alumni Ave., University of Rhode Island, Kingston, RI 02881, USA. E-mail: jt_richard@uri.edu

\author{
Abbreviations \\ $\% \mathrm{~B} / \mathrm{B}$ : percent analyte bound to the antibody \\ divided by the maximum possible binding to \\ the antibody \\ CL: corpus luteum \\ COA: coefficient of association \\ $\mathrm{CV}$ : coefficient of variation \\ GP: genital presents \\ SD: standard deviation \\ TTV: total testicular volume
}

This article is part of the special cluster Beluga whales (Delphinapterus leucas): knowledge from the wild, human care and TEK, which has been funded by Mystic Aquarium, CAFF and the Norwegian Ministry of Climate and Environment.

\section{Introduction}

The inherent link between reproductive behaviour and population dynamics necessitates an understanding of mating strategies to aid population management. As some mating strategies may be more resilient to perturbation than others, understanding the strategies employed by a species is important information when faced with rapid environmental change (Quader 2005) or at low population densities (Møller \& Legendre 2001). Beluga (Delphinapterus leucas) behaviour is influenced by sea-ice loss (O'Corry-Crowe et al. 2016), and for several stocks of belugas with small population sizes, the lack of recovery (Wade et al. 2012) has not been adequately explained. Therefore, understanding beluga mating strategies is critical for the successful conservation and management of this species, especially among small populations under anthropogenic pressures.

Belugas breed in the late winter or early spring, when most populations are inaccessible to human observers (Burns \& Seaman 1988). In summer and fall, when belugas use more readily observable estuarine habitats in much of their range, they are often sexually segregated (Michaud 2005). Beluga mating strategies have been inferred primarily using morphological characteristics and population demographics to be polygynous or polygynandrous ( $\mathrm{O}^{\prime}$ Corry-Crowe et al. 1997; Kelley et al. 2014). However, direct observations during the breeding season are unavailable to confirm these inferences. Similarly, male-male relationships are considered important, perhaps for cooperation related to mating (O'Corry-Crowe et al. 2020), but direct observations are unavailable during the breeding season. When compared 
with other odontocetes, both pre- and post-copulatory selections are presumed to be relatively weak in belugas because of the lack of obvious male weaponry, undocumented behavioural displays for demonstrating male quality, relatively small degree of sexual size dimorphism and reduced investment in testes size (Dines et al. 2015).

Integrating the available information on beluga reproductive anatomy and physiology could help to elucidate potential mating strategies. Belugas have relatively low circulating testosterone concentrations (Høier \& Heide-Jørgensen 1994; Robeck, Monfort et al. 2005), small testes with reduced seasonal variation (Richard, Schmitt et al. 2017) and small ejaculate volumes (O'Brien et al. 2008) compared to other odontocetes, for example, bottlenose dolphin (Tursiops truncatus [Schroeder \& Keller 1989; Robeck, Steinman et al. 2005; Orbach et al. 2019]). The female beluga reproductive tract is less complex (fewer vaginal folds and shorter cumulative length of vaginal folds) than several odontocete species known to engage in sperm competition, in which these folds may allow for sperm selection or limit penile penetration (Orbach et al. 2017). In aquaria, most beluga conceptions occur after testes begin to regress and testosterone concentrations begin to fall (Robeck, Steinman et al. 2005; Richard, Schmitt et al. 2017), in contrast to convention in vertebrates, including other odontocetes (Wells 1984; Wingfield et al. 1990; Wu et al. 2010). Taken together, these observations suggest a reduced role for sperm competition or male contest competition relative to other species of cetaceans. These findings could all be related to the recent discovery that belugas are facultative-induced ovulators (Steinman et al. 2012).

When compared to mammals with spontaneous ovulation, mammals with an induced mode of ovulation often display different reproductive behaviour because malemale post-copulatory competition is reduced. With induced ovulation, the ability of an individual male to monopolise paternity is generally increased, with the first male copulating with the female most likely to sire the offspring (Lacey et al. 1997; Soulsbury 2010). Reduced male-male post-copulatory competition among species with induced ovulation is associated with smaller testes sizes and lower sperm concentrations per ejaculate when compared to spontaneously ovulating species (Iossa et al. 2008; Soulsbury \& Iossa 2010). With weak post-copulatory competition, females are expected to employ pre-copulatory mate selection. Males would be expected to have variation in mating behaviours or other traits that could facilitate mate selection, and females would be expected to behave variably towards individual males, depending on the female's reproductive state (Orbach et al. 2015). Therefore, to describe the mating strategies of a species most accurately, it is necessary to determine the reproductive condition of an individual at the time that reproductive behaviour is observed (e.g., Muraco \& Kucjaz 2015).
Gonad function, measured through testes size, spermatogenic activity or follicular development, is an indicator of an individual's reproductive condition and is often used to assess maturity and reproductive condition in adult odontocetes (Neimanis et al. 2000; Muraco \& Kucjaz 2015). Reproductive steroid hormone measurements can be used to detect changes in gonad function, and therefore reproductive condition. Therefore, studies that correlate steroid hormone concentrations and behaviour in wild animals are common across taxa, including several species of marine mammals (Bartsh et al. 1992; Burgess et al. 2012). However, sample matrices typically used to assess steroid hormone concentrations in cetaceans are either invasive (blood or blubber) or difficult to collect from free-swimming animals (urine or faeces). As a result, paired studies of reproductive behaviour and endocrinology in cetaceans are rare, even in aquaria, but yield important insights on the reproductive biology of a species (Wells 1984; Robeck et al. 1993; Wu et al. 2010; Muraco \& Kucjaz 2015).

The physiological validation of blow (exhale) sampling for reproductive steroid hormone analysis in belugas (Richard, Robeck et al. 2017) facilitates repetitive sampling in real time and, thus, improves the feasibility of paired studies of beluga reproductive behaviour and endocrinology. This is especially true in aquaria, where underwater visibility and year-round access have allowed descriptive studies of reproductive behaviour (Glabicky et al. 2010; Hill et al. 2015; Hill et al. 2018). However, observations of beluga reproductive behaviour have not yet been evaluated in the context of reproductive physiology, preventing discrimination of courtship behaviour from socio-sexual behaviour, which is common among odontocetes (Mann 2006). Whilst a study of belugas in an aquarium cannot be used to infer the mating system or specific reproductive strategies of all wild belugas, the more intensive data collection that is possible in this setting can provide valuable information that can be used to inform studies of wild belugas.

In this study, minimally invasive methods were used to assess the relationship between reproductive physiology and behaviour of a group of aquarium belugas. Based on our understanding of beluga physiology and wild beluga behaviour, female-male interactions were expected to be seasonal, and courtship behaviour was expected to occur most frequently when females were most receptive (the follicular phase of the oestrous cycle), which is most likely to occur after testosterone concentrations and testes size decline. Male-male interactions were not expected to vary in frequency seasonally and were unlikely to be characterised by intense aggression. Following predictions based on ovulation mode and reproductive anatomy in this species, a low copulation rate and opportunities for females to employ pre-copulatory mate choice were expected to occur. 


\section{Methods}

This study was conducted on four belugas (two females: F1 and F2; two males: M1 and M2) housed at Mystic Aquarium (Mystic, CT) in a 2.8 million litre outdoor exhibit chilled to temperatures $<16{ }^{\circ} \mathrm{C}$. Most of the exhibit is visible from underwater through large acrylic windows. Behavioural observations and physiological measurements were performed for one year (52 consecutive weeks, henceforth numbered consecutively from 1 to 52) from 25 August 2013 to 21 August 2014. F2 was only available for the first 21 weeks of the study (Table 1). This project was approved by the Institutional Animal Care and Use Committees of Mystic Aquarium (project no. 12001) and the University of Rhode Island (project no. AN12-02-016).

\section{Physiological assessments of reproductive condition}

Blow (exhale) samples were collected twice per week from the males and once per week from the females with the voluntary cooperation of the whale and analysed as described by Richard, Robeck et al. (2017). Blow samples were collected in the morning hours between 09:00 and 1 1:30 and stored at $-80{ }^{\circ} \mathrm{C}$ until analysis. Blood sampling utilising trained behaviour was attempted once or twice per month with $\mathrm{Fl}$ as a part of routine veterinary monitoring. Blood samples were collected into sodium heparinised vacutainer tubes from the ventral fluke vein. One millilitre of serum or sodium heparin plasma was obtained through centrifugation $\left(2000 \times \mathrm{g}\right.$ for $10 \mathrm{~min}$ at $\left.10^{\circ} \mathrm{C}\right)$ and stored at $-80{ }^{\circ} \mathrm{C}$ until analysis. Male samples were assayed for testosterone, and female samples were assayed for progesterone using enzyme immunoassays (Cayman Chemical, Ann Arbor, MI; item nos. 582701 and 582601) previously validated for use with beluga blow and blood samples (Richard, Robeck et al. 2017). All samples were assayed in duplicate, and the means were used in calculations. Individual samples with a \%B/B between 20 and $80 \%$ and a CV below $20 \%$ were accepted. If sufficient volume was available, samples with CV $>20 \%$ were re-assayed. When available, multiple samples collected within the same week were averaged to obtain weekly testosterone values. Two standard controls were run in each assay (testosterone: 100 and $25 \mathrm{pg} / \mathrm{ml}, n=12$ assays; progesterone: 200 and $50 \mathrm{pg} / \mathrm{ml}, n=14$ assays). Inter-assay variation was calculated by determining the CV for the two standard controls on each plate. Intra-assay variation was calculated by averaging the CV for all of the samples with $20-80 \%$ binding on each plate. Testosterone intra-assay variation was $7.7 \%$; inter-assay variation was $5.7 \%$ for the $100 \mathrm{pg} /$ $\mathrm{ml}$ control and $10.8 \%$ for the $25 \mathrm{pg} / \mathrm{ml}$ control. Progesterone intra-assay variation was $11.7 \%$; inter-assay variation was $5.8 \%$ for the $200 \mathrm{pg} / \mathrm{ml}$ control and $15.5 \%$ for the $50 \mathrm{pg} / \mathrm{ml}$ control. The average lower limit of detection $(80 \% \mathrm{~B} / \mathrm{Bo})$ was $10.9 \mathrm{pg} / \mathrm{ml}$ for testosterone and 30.5 $\mathrm{pg} / \mathrm{ml}$ for progesterone. All biological samples assayed exceeded the lower limit of detection. Some of the hormone measurements in blow samples have been presented previously (Richard, Robeck et al. 2017) and so are only reported here to contextualise behavioural observations.

The occurrence of ovulation in Fl was inferred through progesterone measurements in blow and blood, using known oestrous cycle stage lengths in belugas reported by Steinman et al. (2012); ultrasonographic data were unavailable in this study. Ovulation leads to an increase in progesterone concentrations in beluga blow (Richard, Robeck et al. 2017). Specifically for Fl, the presence of a CL (confirmed via ultrasonography) was associated with an increase in blow progesterone that lasted approximately 20 days, from a baseline of $248.5 \pm 62.5 \mathrm{pg} / \mathrm{ml}$ to $326.5 \pm 33 \mathrm{pg} / \mathrm{ml}$ (mean \pm SD; Richard, Robeck et al. 2017). High progesterone would be indicative of the luteal phase, which lasts 29-32 days in non-conceptive cycles (Steinman et al. 2012). To minimise the chance of a false positive, ovulation was inferred to have occurred if two consecutive weekly samples exceed $326.5 \mathrm{pg} / \mathrm{ml}$, the mean progesterone concentration during Fl's luteal phase monitored by Richard, Robeck et al. (2017). The follicular phase, which lasts 14-27 days (Steinman et al. 2012), was conservatively presumed to occur in the week that ovulation was inferred to have occurred on the basis of an elevated progesterone measurement, as well as the two weeks preceding the week of ovulation. The follicular phase could overlap with the luteal phase of a previous non-conceptive cycle, as reported by Steinman et al. (2012). Inferred ovulations must be

Table 1 Study animals and samples.

\begin{tabular}{|c|c|c|c|c|c|c|c|}
\hline Individual $^{a}$ & Age $^{b}$ & Length $^{\mathrm{C}}(\mathrm{cm})$ & $\operatorname{Mass}^{\mathrm{C}}(\mathrm{kg})$ & Reproductive status & No. of blow samples & No. of blood samples & No. of ultrasound exams \\
\hline$\overline{\mathrm{F} 1}$ & 32 & 335 & 659 & Nulliparous & 51 & 14 & - \\
\hline $\mathrm{F} 2$ & 32 & 335 & 727 & Nulliparous & 14 & - & - \\
\hline M1 & 27 & 399 & 945 & Proven sire & 96 & - & 23 \\
\hline M2 & 11 & 390 & 723 & No offspring sired & 104 & - & 15 \\
\hline
\end{tabular}

a Male (M) and female (F). ${ }^{b}$ Age of the animal at the beginning of the study period. ${ }^{c}$ Measured once during the study period. 
separated by at least 30 days, given the inter-oestrous interval of 33-34 days (Steinman et al. 2012).

TTV was determined using ultrasonography performed with the voluntary cooperation of the whale as described by Richard, Schmitt et al. (2017). Exams were conducted twice per month by a single operator using a convex 3.5 $\mathrm{MHz}$ probe (GE Logiq Book with 3C-RS transducer, GE Medical Systems, China).

\section{Behavioural observations}

An ethogram was developed using published descriptions of beluga behaviour (DiPaola et al. 2007), as well as pilot observations of the study group performed in the breeding season (February-April) of the previous year (Table 2). Behaviour names were later refined to be consistent with publications available after the start of the study (Hill et al. 2015; Muraco \& Kucjaz 2015). A social interaction was defined as occurring when two or more whales are performing any of the social behaviours listed in the ethogram. Of particular interest was the 'genital present' (Fig. 1), which is similar to the pelvic thrust described by Glabicky et al. (2010) and a combination of the horizontal 'S' posture and pelvic thrust behaviours described by Hill et al. (2015). The definition used in this study removes any orientation restrictions on the occurrence of the behaviour, identifies the necessary presence of a recipient, separates this behaviour from copulation, accounts for the cessation

Table 2 Ethogram of social behaviours of interest.

\begin{tabular}{|c|c|}
\hline Behaviour & Definition \\
\hline \multicolumn{2}{|l|}{ States } \\
\hline Milling & $\begin{array}{l}\text { Two or more whales actively swim, drift passively or lie still with no discernible pattern or in variable directions within } 4 \mathrm{~m} \text { of each } \\
\text { other; may be associated with social events. }\end{array}$ \\
\hline Group swim & $\begin{array}{l}\text { Two or more whales swim in the same direction at approximately the same velocity for at least } 30 \text { seconds; all whales are within } \\
2 \mathrm{~m} \text { of at least one other whale in the group; bodies can be aligned or staggered (one whale swims ahead of the other), but one } \\
\text { whale may not be completely behind another; body orientation of individuals may vary. }\end{array}$ \\
\hline \multicolumn{2}{|l|}{ Events } \\
\hline Approach & $\begin{array}{l}\text { A whale alters swim direction or speed to initiate interaction with another whale(s), whilst the other whale(s) does not alter swim } \\
\text { speed or direction; resulting position is less than } 4 \mathrm{~m} \text { from recipient whale; interaction is initiated. }\end{array}$ \\
\hline Separate & $\begin{array}{l}\text { A whale alters swim direction or speed to terminate interaction with another whale(s), whilst the other whale(s) does not alter } \\
\text { swim direction or speed; resulting position is at least } 4 \mathrm{~m} \text { from previously interacting whale(s), terminating the interaction. }\end{array}$ \\
\hline Open mouth & A whale opens mouth wide enough so that the tongue is (or would be) visible. \\
\hline Mouthing & A whale makes contact with another whale with an open mouth. \\
\hline Erection & $\begin{array}{l}\text { Any part of the penis is visible during any social interaction; it may occur simultaneously with any other social behaviour in this } \\
\text { ethogram. }\end{array}$ \\
\hline Head nod & $\begin{array}{l}\text { A whale moves the head in a dorsal/ventral plane at least two times in succession without shaking the melon. Mouth may be } \\
\text { opened or closed. }\end{array}$ \\
\hline Flutter & $\begin{array}{l}\text { An atypical swimming motion in which the flukes are moved with greater tailbeat frequency at smaller amplitudes for at least } \\
\text { three successive tailbeats, resulting in the shaking of the abdominal fat pads. }\end{array}$ \\
\hline Genital present & $\begin{array}{l}\text { Whale stops active forward progress by terminating fluke beating and drifts in the direction of another whale whilst arching } \\
\text { their caudal peduncle, so that the genital region is pushed closer to the recipient whale; caudal end of the caudal peduncle } \\
\text { is correspondingly angled dorsally; rostrum is often directed towards the recipient whale for some portion of the presentation } \\
\text { causing the body to assume an 'S' shape; flukes and flippers may be held at various angles to control the drift towards the } \\
\text { recipient whale; it may result in contact of the genital region with the recipient. }\end{array}$ \\
\hline
\end{tabular}
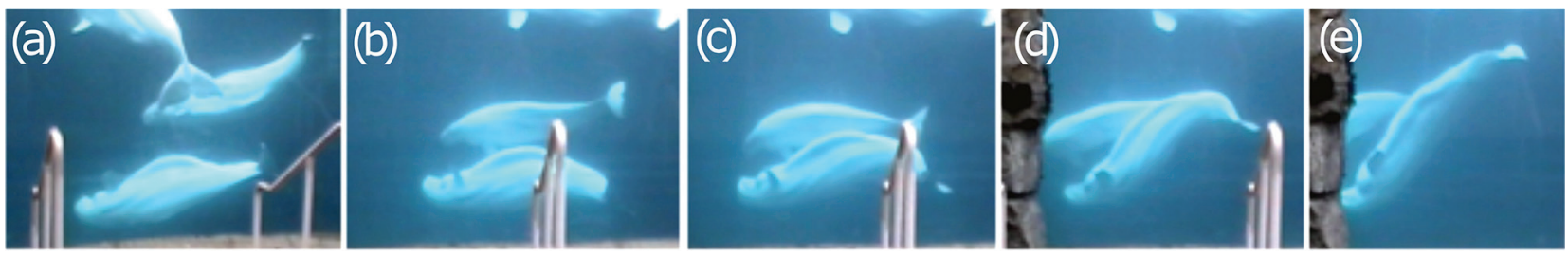

Fig. 1 A sequential view of a genital present from a male (bottom of frame) towards a female (centre of frame). Note the ventral orientation of the female relative to the male in (a) and the lateral orientation relative to the male by (c), in which the female's ventral surface was rolled away from the male. The ' $S$ ' shape is clear in (d). 
of active swimming and reduces the implication that the behaviour is forcible. One whale length (ca. $4 \mathrm{~m}$ ) was used as a distance frame of reference for several behaviours. The recipient of a behaviour in a social interaction with more than two whales was determined by the direction of the actor's rostrum during a behavioural event.

Observation protocol. Four hours of observations were conducted per week: two hours in the morning between 07:00 and 10:00 and two hours in the afternoon between 15:00 and 18:00, for a total of $208 \mathrm{hr}$ of observation completed in 211 observation sessions lasting 30-90 min each. Continuous observations of the social group were conducted using a tripod-mounted digital video camera at the underwater viewing area. An event sampling rule was used in which the videographer focused filming on any social interaction that occurred during the filming period, regardless of participants, resulting in a continuous record of all social interactions visible from underwater viewing. If social interactions exceeding 1 min in duration occurred in one of the satellite pools that lack underwater viewing, the observer moved and recording was conducted from an above-water vantage point. Observations were only conducted outside of training sessions. Behavioural data were grouped by week (1-52).

Quantifying behaviour. The video material was first analysed for behavioural states by one of two observers. The animals engaging in the interaction were identified, as was the duration of the interaction to the nearest 5 seconds (minimum 5 seconds), and the animal that initiated ('Approach') and terminated ('Separate') the interaction. Approaches and separations may not have been identified for interactions that started or ended prior to or after the observation session or out of view of the camera. The total number of interactions, the average duration of interactions and the total amount of time interacting were calculated for each social grouping and each behavioural state. Weekly COAs were calculated using the simple COA described by Cairns \& Schwager (1987).

In the next stage of analysis, behavioural event frequency was quantified using CowLog software (Hänninen \& Pastell 2009) and continuous recording (Martin \& Bateson 2007) by one of three observers. For each event, the actor, behaviour and recipient were recorded. Behavioural event coding was not possible for interactions that occurred in the satellite pools that lacked underwater viewing, although the occurrence, duration and participants of the interactions in these pools were recorded. Weekly behavioural event frequencies per minute of observation are reported as mean \pm SD.

Genital presents. Every occurrence of a genital present between a male and female was reviewed by a single observer (JTR) to describe the behaviour in greater detail and to determine the recipient's response to the genital present display. The behavioural state and social grouping at the time of the genital present were recorded. The general area of the recipient's body the actor directed the display towards (right lateral, left lateral, ventral or dorsal surface), the relative body position of the actor during the display (horizontal, head angled towards bottom or head angled towards surface) and the position of the whales in the water column (completely submerged or any part of the body at the surface) were also recorded. A 'receptivity score' was developed for the recipient and assigned to each occurrence of a male towards female genital present (Table 3), with higher scores indicating increased receptivity. The body position of belugas during copulation has not been formally described, although intromission attempts are described as ventral to ventral (Hill et al. 2015). Therefore, receptivity was assumed to be characterised by matching swim speeds, presenting the ventral surface towards the actor and allowing physical contact to occur.

Table 3 'Receptivity score' scheme used to assign receptivity to genital presents. Each occurrence received one score from each of the three categories (swim speed, orientation and contact), and the total receptivity score for each genital present is the sum of these three component scores.

\begin{tabular}{ll}
\hline Response & Score \\
\hline Swim speed & 0 \\
Recipient alters swim speed to increase distance from genital present & 1 \\
Recipient continues to make forward progress during genital present (swim speed unchanged) & 2 \\
Recipient stops active swimming and drifts during genital present & 0 \\
Orientation & 1 \\
Recipient rolls ventral surface away from the genital present & 2 \\
Recipient remains stable along long axis so that genital present ends closer to dorsal surface than ventral surface & \\
Recipient rolls ventral surface towards the genital present or remains stable along long axis so that genital present ends closer to & \\
ventral surface than dorsal surface & 0 \\
Contact & \\
Contact does not occur & 2 \\
Contact occurs on recipient's lateral or dorsal surfaces & \\
Contact occurs on recipient's ventral surface & \\
\hline
\end{tabular}


Inter-observer reliability. Inter-observer reliability for the coding of behavioural events was assessed by having all three observers code the same 10 hours of video, containing $133 \mathrm{~min}$ of social interaction (9\% of all interactions). The identity of the participants in an interaction had $100 \%$ agreement between all three observers. For each behavioural event, a pairwise kappa statistic was determined, using observer $\mathrm{l}$ (JTR) as the reference observer. All behaviours had 'excellent' agreement $(\kappa>$ 0.75 ) with observer 1 except mouthing for one observer pairing, which had 'good' agreement $(\kappa=0.63$; Kaufman $\&$ Rosenthal 2009). Inter-observer reliability for the coding of behavioural states was assessed by having both observers code the same 12 hours of video selected from 10 different months, containing $203 \mathrm{~min}$ of social interaction (14\% of all interactions). The occurrence of interactions had $98.5 \%$ agreement between the two observers. The identifications of the behavioural states for these interactions had 'excellent' agreement $(\kappa>0.75$; Kaufman $\&$ Rosenthal 2009).

\section{Data analysis}

Because of the small sample size and repeated sampling, statistical tests were not performed. Descriptive statistics (mean $\pm \mathrm{SD}$ ) were used to describe variation in female-male association or specific behaviours with $\mathrm{Fl}$ 's reproductive state. F2 was not in the social group during the time period when belugas are typically reproductively active, had no evidence of ovarian activity during the weeks she was observed, was only involved in $7 \%$ of all social interactions and did not receive any genital present behaviours. Therefore, any descriptions of courtship behaviour will be in reference to Fl. 'Breeding season' is defined as the period of time lasting from the week containing the start of Fl's first inferred follicular phase through the week containing the start of the last luteal phase as determined via progesterone measurements in blow. Fl's receptivity towards genital presents performed by $\mathrm{Ml}$ and M2 was compared by calculating Cohen's $d$ to estimate the effect size. Box plots created in R (R Core Team 2020) show the interquartile range (box), the median (bold line) and the maximum (Q3) or minimum value $\leq 1.5$ times the interquartile range (whiskers).

\section{Results}

\section{Progesterone assays}

Once weekly once blow samples were available for Fl (Table 4). For F2, blow sample volumes were commonly too small to assay, so that only 13/21 weeks were sampled. Progesterone data are presented in Table 4. Elevated progesterone was not observed in any blow samples collected from F2. A total of 12 F1 blow samples exceeded the elevated progesterone concentration of $326.5 \mathrm{pg} / \mathrm{ml}$ (weeks 12, 20, 35-36, 38-39, 42 and 44-48). None of the blood samples collected from Fl during the study had progesterone concentrations indicative of luteal activity, although there was a 65-day gap in sampling between March and May. Three periods met the requirements for inferring ovulation: weeks 35-36 (20 April-3 May), weeks 38-39 (11 May-24 May) and weeks 44-48 (22 June-26 July). Using blood progesterone values to rule out active luteal phases and accounting for the 7-10-day gaps between sampling, corresponding follicular phases were inferred to span weeks 31-33 (23 March-12 April), 35-37 (20 April-10 May) and 43-45 (15 June-5 July). 'Breeding season' will be defined as weeks 31-46. None of the inferred ovulations resulted in a detectable pregnancy.

\section{Male physiological assessments}

Two blow samples per week were available for all weeks for Ml except weeks 3, 25, 36, 39, 42, 42, 50 and 51, when only a single sample was available for assay. Two samples per week were available for all weeks for M2 except weeks 35, 39 and 42. Ml's testosterone (107.0 \pm $39.9 \mathrm{pg} / \mathrm{ml}$ ) peaked during week 26 (207.7 pg/ml) and remained elevated above the mean from week 15 to week 36, with the exception of two weeks. M2's blow testosterone concentration $(97.0 \pm 44.4 \mathrm{pg} / \mathrm{ml})$ peaked in week 29 (277.1 pg/ml) and remained elevated above the mean from week 26 to week 39, with the exception of one week. Ml's TTV $\left(993.3 \pm 129.0 \mathrm{~cm}^{3}\right)$ peaked in week 24 (1306.4 $\mathrm{cm}^{3}$ ) and remained, with the exception of one measurement, elevated above the mean from week 18 to 38. M2's TTV $\left(294.5 \pm 32.7 \mathrm{~cm}^{3}\right)$ never exceeded $366.0 \mathrm{~cm}^{3}$, beginning with the first available measurement in week 23 .

\section{Behavioural observations}

Social interactions were observed in 197 of the 211 observation sessions and comprised 12\% (1437 min in 2396 separate interactions) of the total time observed. A total of $45.2 \mathrm{~min}$ of interactions (3.1\% of total interaction time) occurred in pools that lacked underwater viewing, and

Table 4 Progesterone concentrations $(\mathrm{pg} / \mathrm{ml})$ from blood and blow for female belugas F1 and F2.

\begin{tabular}{lcccc}
\hline ID & $\begin{array}{c}\text { Sample } \\
\text { type }\end{array}$ & $\begin{array}{c}\text { No. of } \\
\text { observations }\end{array}$ & Mean \pm SD & Range \\
\hline F1 & Blow & 52 & $291.1 \pm 90.8$ & $156.5-763.8$ \\
F2 & Blow & 13 & $250.9 \pm 49.8$ & $143.76-312.1$ \\
F1 & Blood & 14 & $473.7 \pm 111.1$ & $293.1-710.2$ \\
\hline
\end{tabular}


therefore lacked behavioural event data. Interactions with Fl were comprised mostly of group swim interactions (by duration), whilst M1-M2 interactions were primarily milling interactions (Table 5). Female-male group swims often lasted several minutes, with maximum observed durations of 32 (M1) and 50 (M2) minutes. The approaching whale was identified for 2124 of the interactions $(89 \%)$. The separating whale was identified for 2086 of the interactions $(87 \%)$. Of all male-Fl interactions, males initiated $94 \%$ and terminated $27 \%$. Of the male-male interactions, M2 initiated $80 \%$ and terminated $42 \%$.

\section{Variation in behaviour with F1's breeding season}

Interactions involving males and females occurred in every week of the year, and in $74 \%$ of the observation sessions. However, COA varied widely throughout the year, with $70 \%$ of all male-F1 interaction (597 min) occurring during the 16-week breeding season (30\% of weeks; Fig. 2). Female-male COA was $0.107 \pm 0.144$ during Fl's inferred follicular phases and was $0.218 \pm$ 0.174 during other weeks of the breeding season. Fl initiated more interactions (7.1\% vs. $2.7 \%)$ and terminated fewer interactions $(63.3 \%$ vs. $80.2 \%)$ during the breeding season than during other times of the year. There was less seasonal variability in interactions that only involved males; $35 \%$ of all male-male interaction (170 min) occurred during the breeding season.

The frequency of behaviours performed during interactions in relation to Fl's breeding season is presented in Table 6. All male towards Fl behaviours were more frequent during the breeding season except mouthing, which was rarely observed. Male display behaviours (genital presents, melon shakes, head nods and flutters) occurred 14.8 times more frequently during the breeding

Table 5 Amount of time in minutes spent interacting by group and behavioural state for male (M1 and M2) and female (F1) belugas.

\begin{tabular}{|c|c|c|c|c|c|}
\hline \multirow[t]{2}{*}{ Social group } & \multirow{2}{*}{$\begin{array}{c}\text { Duration of } \\
\text { interactions (min) }\end{array}$} & \multicolumn{2}{|c|}{ Milling } & \multicolumn{2}{|c|}{ Group swim } \\
\hline & & Proportion of total duration & Duration per interaction & Proportion of total duration & Duration per interaction \\
\hline M2-F1 & 605.5 & 0.18 & $0.24 \pm 0.39$ & 0.82 & $4.36 \pm 7.92$ \\
\hline M1-M2-F1 & 175.2 & 0.12 & $0.27 \pm 0.19$ & 0.88 & $3.10 \pm 5.34$ \\
\hline$M 1-M 2$ & 485.3 & 0.90 & $0.33 \pm 0.46$ & 0.10 & $1.27 \pm 0.80$ \\
\hline
\end{tabular}
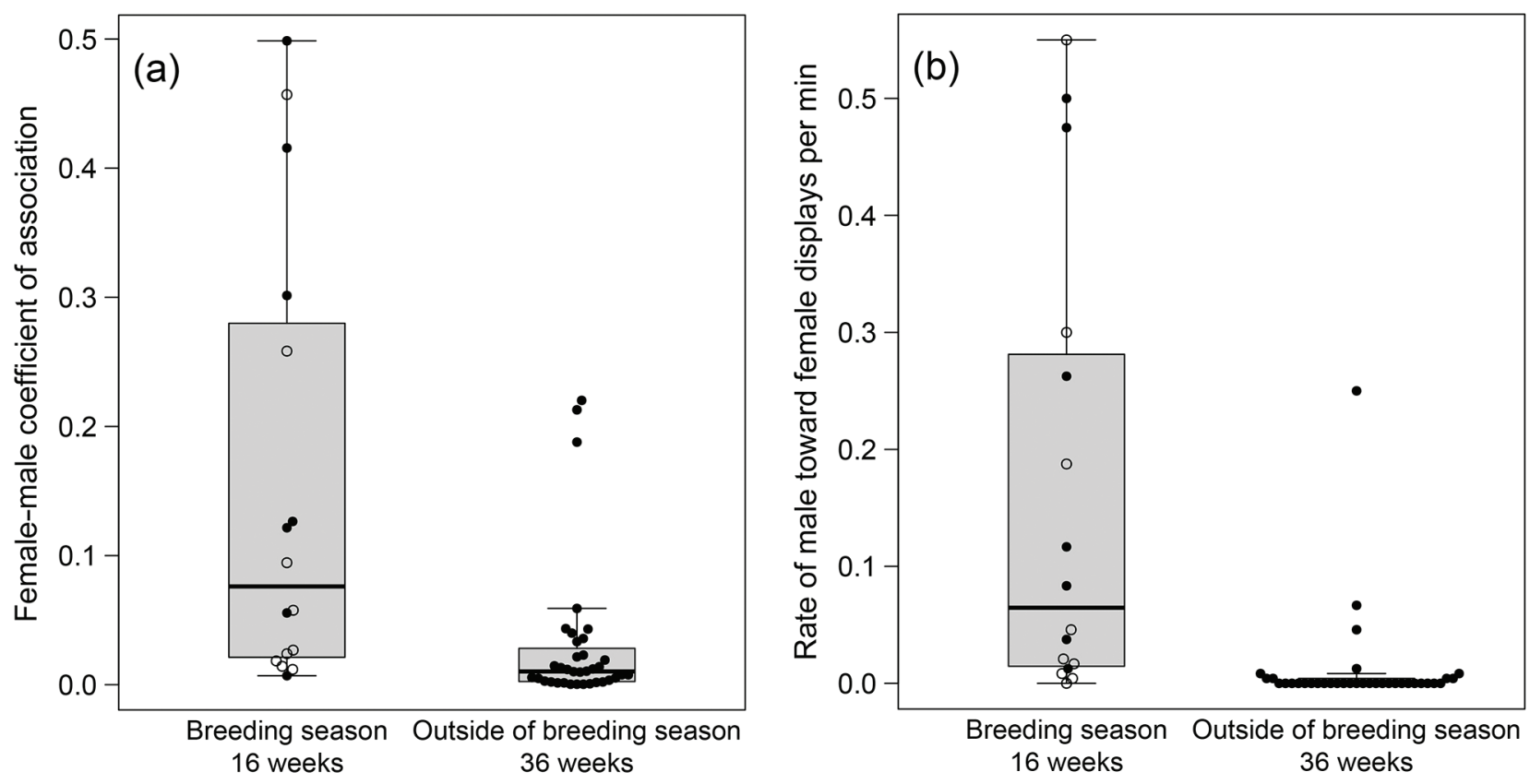

Fig. 2 Box plots of (a) weekly female-male COAs between the males and female F1 and (b) the weekly rates per minute of male display behaviours (genital present, melon shake, head nod and flutter) towards F1 relative to F1's breeding season. Open circles indicate weeks during F1's inferred follicular phases. 
Table 6 Variation in behaviour for male (M1 and M2) and female (F1) belugas relative to F1's reproductive condition, during the breeding season (weeks 31-46) compared to outside of the breeding season.

\begin{tabular}{|c|c|c|}
\hline Behaviour & Breeding season (mean \pm SD) & Outside breeding season (mean \pm SD) \\
\hline Female-male COA & $0.16 \pm 0.17$ & $0.03 \pm 0.06$ \\
\hline Male-only COA & $0.044 \pm 0.035$ & $0.036 \pm 0.023$ \\
\hline Proportion of M-F1 interactions: group swim & $0.61 \pm 0.42$ & $0.26 \pm 0.32$ \\
\hline Duration of M-F1 interactions (seconds) & $103.72 \pm 314.78$ & $31.12 \pm 76.66$ \\
\hline Duration of M-M interactions (seconds) & $25.8 \pm 35.22$ & $20.75 \pm 30.87$ \\
\hline Behaviours directed to F1 & $\begin{array}{l}\text { Breeding season frequency per } \\
\text { minute observed (mean } \pm \text { SD) }\end{array}$ & $\begin{array}{c}\text { Outside breeding season frequency per } \\
\text { minute observed (mean } \pm \text { SD) }\end{array}$ \\
\hline Genital present & $0.064 \pm 0.085$ & $0.004 \pm 0.016$ \\
\hline Open mouth & $0.149 \pm 0.169$ & $0.024 \pm 0.033$ \\
\hline Melon shake & $0.074 \pm 0.097$ & $0.005 \pm 0.015$ \\
\hline Mouthing & $0.0003 \pm 0.001$ & $0.001 \pm 0.002$ \\
\hline Flutter & $0.006 \pm 0.007$ & $0.001 \pm 0.004$ \\
\hline \multicolumn{3}{|l|}{ Behaviours performed by F1 } \\
\hline Genital present & $0.016 \pm 0.032$ & 0 \\
\hline Open mouth & $0.065 \pm 0.09$ & $0.003 \pm 0.004$ \\
\hline Melon shake & $0.019 \pm 0.036$ & 0 \\
\hline Mouthing & 0 & 0 \\
\hline Head nod & $0.008 \pm 0.016$ & 0 \\
\hline Flutter & 0 & 0 \\
\hline \multicolumn{3}{|l|}{ Behaviours performed between M1 and M2 } \\
\hline Genital present & $0.027 \pm 0.071$ & $0.011 \pm 0.026$ \\
\hline Open mouth & $0.096 \pm 0.061$ & $0.086 \pm 0.058$ \\
\hline Melon shake & $0.004 \pm 0.007$ & $0.004 \pm 0.008$ \\
\hline Mouthing & $0.028 \pm 0.024$ & $0.029 \pm 0.038$ \\
\hline
\end{tabular}

season $(0.164 \pm 0.188$ behaviours $/ \mathrm{min})$ than outside of the breeding season $(0.011 \pm 0.042$ behaviours/min; Fig. 2). Copulation was not observed. Erections were rarely seen during male-female interactions (two from $\mathrm{Ml}$ and one from M2). Both erections observed from Ml occurred with a genital present towards F1 during breeding season (weeks 33 and 35). The frequencies of malemale behaviours were similar in and out of breeding season except for genital presents (breeding season: 0.027 \pm 0.071 and non-breeding season: $0.011 \pm 0.026)$.

Male-towards-female genital presents occurred in 27 different observation sessions (13\% of sessions). These 27 sessions also contained a majority of the occurrences of group swim $(83 \%)$, open mouth $(61 \%)$, melon shake $(87 \%)$, head nod $(79 \%)$ and flutter $(74 \%)$. Only 2 of those 27 sessions contained genital presents from both males towards F1. Genital presents occurred during group swim $98 \%$ of the time. Ml performed $70 \%$ of his genital presents to Fl during her inferred follicular phases, compared to $37 \%$ of M2's genital presents towards F1 (Fig. 3). Neither male was observed performing a genital present towards Fl during her third inferred follicular phase in weeks 43-45. Ml was not observed to perform a genital present towards F1 between 26 April and 30 July, whilst M2 performed $75 \%$ of his genital presents towards F1 during that period. No male towards male genital presents were observed in sessions when a male towards female genital present was also observed. All of Fl's genital presents were performed towards M2 in sessions where M2 also displayed a genital present towards F1.

Fl's breeding season, and therefore much of the female-male behaviour observed, occurred after testosterone concentrations in blow started to decline for both males and testes size started to decline in Ml (Fig. 3). Mean individual female-male COAs and display behaviour frequencies towards Fl were highest for both males whilst testosterone was declining from the peak measurement (Fig. 4). M2 associated with F1 (781 min) more often than Ml (249 $\mathrm{min}$ ) and performed more behavioural events towards Fl (1193) than Ml (324). Fl's head nods (100\%), melon shakes (99\%) and open mouths $(99 \%)$ were almost exclusively directed towards M2. However, during F1-M1-M2 interactions, F1 received more behavioural events from Ml (174) than from M2 (57), with genital presents showing the greatest disparity (84 from M1 and 5 from M2). 


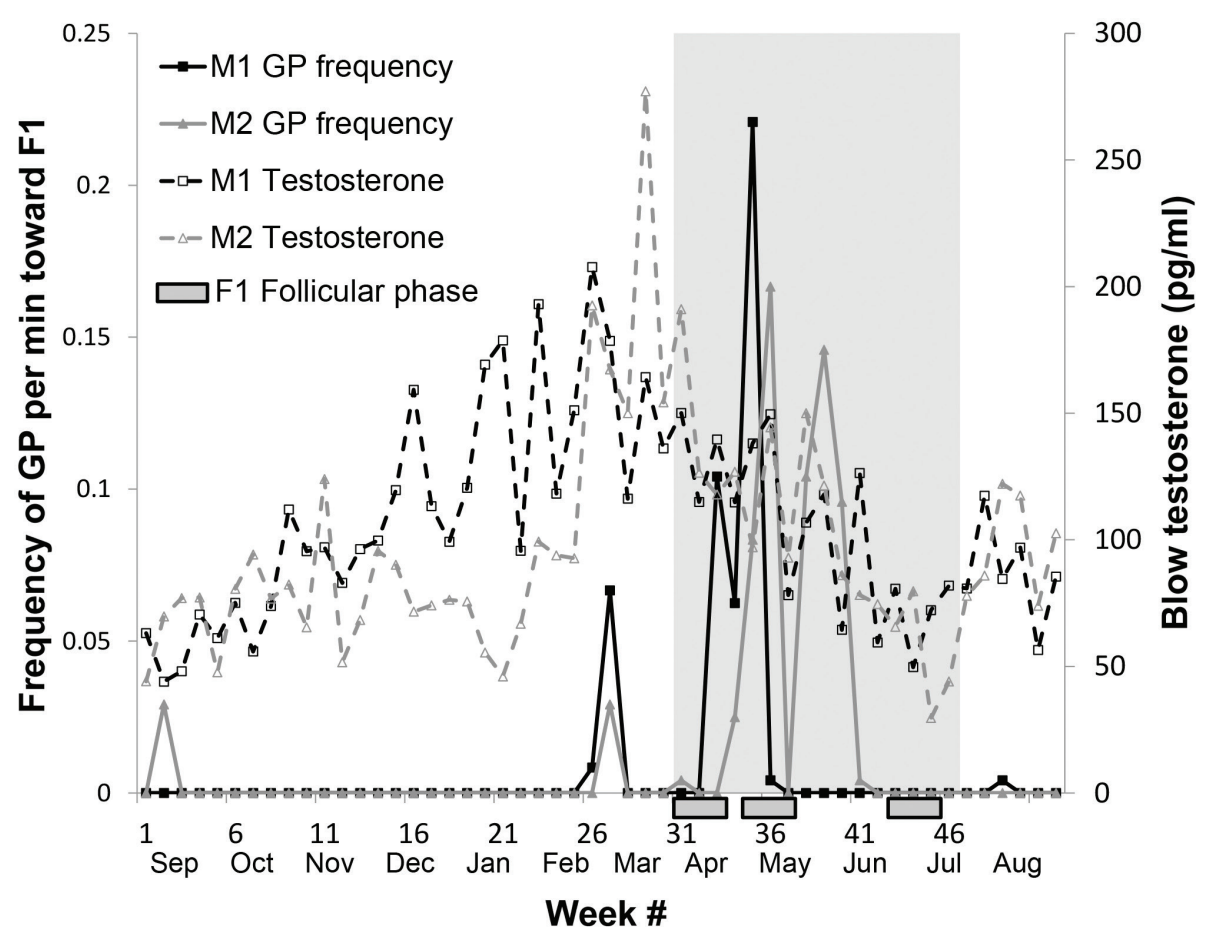

Fig. 3 Variation in the frequency of GP performed by the males (M1 and M2) towards the female F1 per minute of observation in relation to testosterone concentrations in blow and F1's breeding season (shaded area) and inferred follicular phases (indicated along the $\mathrm{x}$ axis with grey bars).
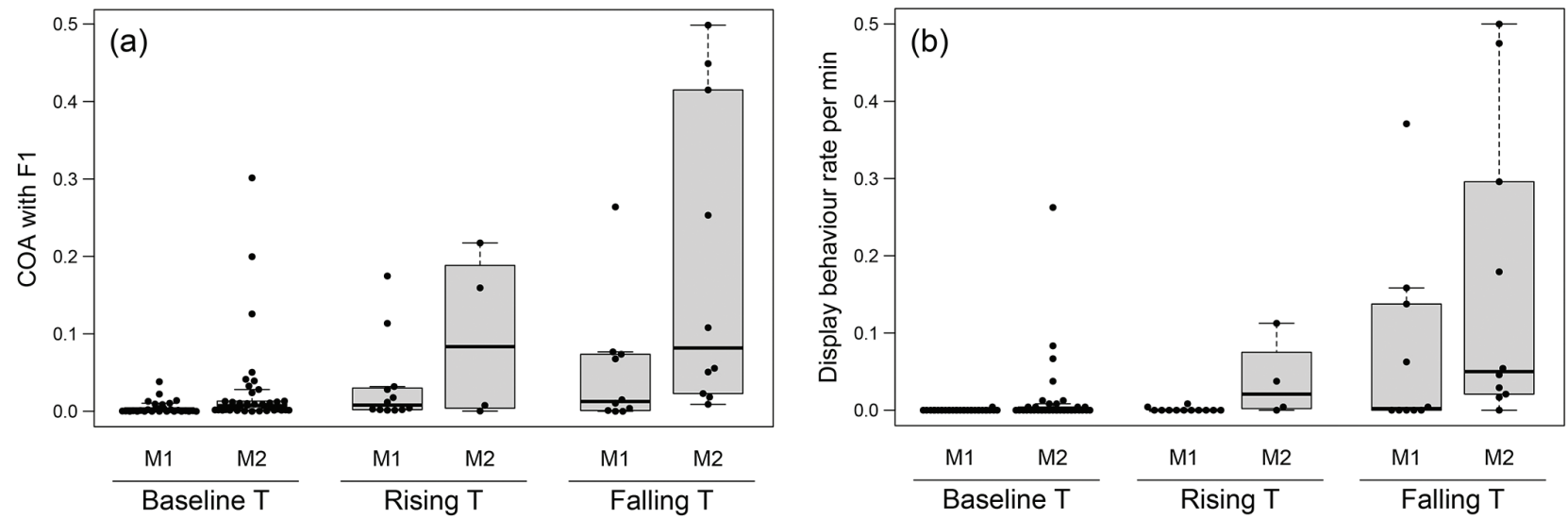

Fig. 4 Box plots of weekly female-male COAs (a) between the males (M1 and M2) and female F1 and (b) the weekly rates per minute of male display behaviours (genital present, melon shake, head nod and flutter) towards F1 relative to weekly testosterone (T) concentrations in blow. 'Rising T' lasted from the first weekly concentration above the individual's annual mean concentration that was followed by a second consecutive week above the mean until the peak weekly concentration. 'Falling T' lasted from the week immediately following the peak concentration until the last week prior to the week before the concentration fell below the mean for at least two consecutive weeks. 'Baseline T' corresponds to all other weeks.

\section{F1's receptivity to genital present displays}

Genital presents performed towards Fl's lateral surface were most frequent ( $84 \%$ of all genital presents), with approximately equal frequency towards Fl's left or right side. Ml presented towards Fl's ventral surface (11\% of genital presents) more often than M2 $(4 \%$ of genital presents). Males performed this behaviour with their long axis parallel to the bottom or with their head angled down towards the bottom; there were no observations of this behaviour with the male's head angled towards the surface. This behaviour was not performed by either male at the water's surface. 
The identity of the male performing a genital present had a large effect on Fl's receptivity scores $(d=1.13)$. Fl's receptivity towards genital present displays from Ml was higher on average and reached higher scores than receptivity towards M2's genital present displays (M1: $2.58 \pm$ 1.02 , range $=1-6 ; \mathrm{M} 2: 1.60 \pm 0.94$, range $=0-4 ;$ Fig. 5 ). F1 slowed her swim speed during genital presents to match Ml's pace during genital present (68\% of displays) more often than during M2's displays (27\%), resulting in higher rates of contact during Ml's displays (19\% vs. 2\%). Fl never actively distanced herself from Ml's displays but did so for $21 \%$ of M2's displays. F1 rolled her dorsal surface towards the displaying male during $15 \%$ of $\mathrm{Ml}^{\prime} \mathrm{s}$ displays and $31 \%$ of M2's. Fl's receptivity to genital present displays during inferred follicular phases was $2.53 \pm 1.05$ for $\mathrm{M} 1$ and $1.45 \pm 1.10$ for M2. In both observations of genital presents from Ml with an erection, Fl rolled her ventral surface away from Ml, and contact did not occur.

\section{Discussion}

The behaviour and physiology of beluga whales were simultaneously investigated for the first time in this study, with hormone measurements in blow providing important contextual information required to interpret behavioural observations. Exclusively continuous behavioural sampling during observation sessions conducted year-round from an underwater vantage point provided detailed

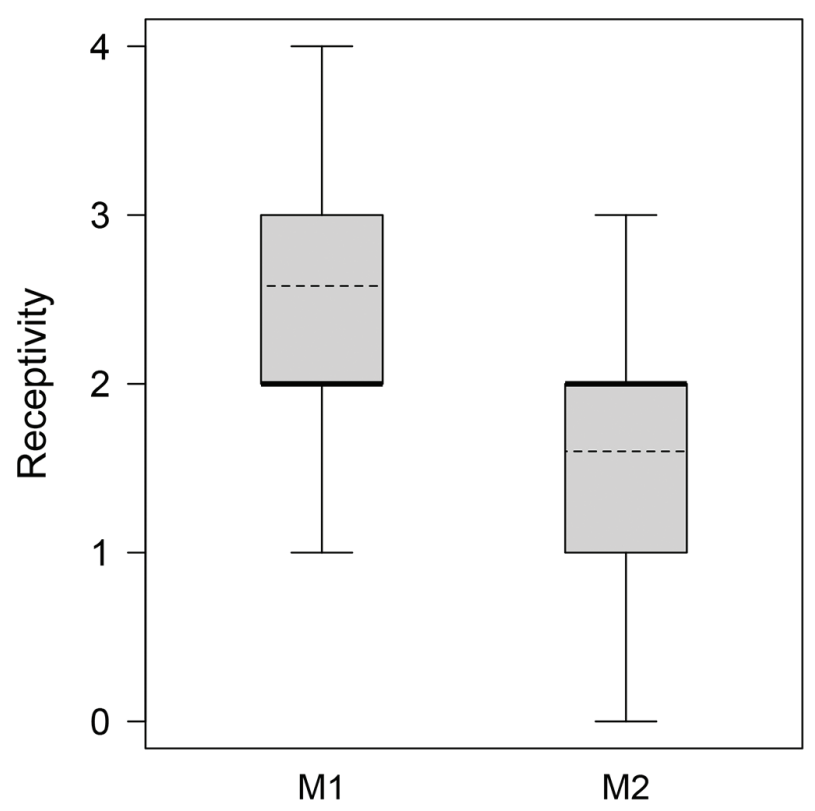

Fig. 5 Female F1's receptivity score by male (M1 and M2) performing the genital present. The solid line within the box represents the median, and the dashed line represents the mean. descriptions of social behaviour that are logistically impossible to perform on wild belugas. Despite the limitations imposed by social grouping and a small sample size, patterns of behaviour were observed that are consistent with beluga behaviour in aquaria (Hill et al. 2018) and the wild. The seasonality of female-male association in this study approximates the seasonal sexual segregation observed in wild belugas (Michaud 2005; Loseto et al. 2006). The lack of apparent seasonality in male-male interactions is consistent with the importance of these associations in wild belugas (O'Corry-Crowe et al. 2020). The high frequencies of female-male association during the time of year when belugas are difficult to observe in the wild emphasise the value of longitudinal studies within aquaria in complementing studies of wild belugas.

Blow sampling for reproductive hormone analysis has value in the longitudinal monitoring of individual animals, as employed in this study (Richard, Robeck et al. 2017). Repeated sampling enabled the identification of Fl's oestrous cycles, which was critical to interpreting patterns of female-male behaviour. In the absence of ultrasonographic or urinary hormone conjugate data, a conservative standard for identifying luteal phases based on previous validations performed with the same animal (Richard, Robeck et al. 2017) was applied to reduce the likelihood of falsely identifying an oestrous cycle. The first two inferred oestrous cycles identified demonstrated expected oestrous cycle stage durations (Steinman et al. 2012), occurred when oestrous cycles frequently occur (Robeck, Monfort et al. 2005) and had female-male behavioural correlates. The third oestrous cycle identified was less clearly interpreted, fell during a time when oestrous cycles are less likely to oestrous (Robeck, Monfort et al. 2005) and lacked behavioural correlates. Although aquarium belugas most often have two oestrous cycles in a given breeding season (Steinman et al. 2012), there are observations of up to seven non-conceptive oestrous cycles in a single year for one female (Katsumata et al. 2006). The progesterone measurement approach precluded the detection of non-ovulatory oestrous cycles, which have been observed in belugas (Steinman et al. 2012). The high level of interest in Fl by the males in February (weeks 26-27; 38\% of all female-male interactions and $72 \%$ of all male towards female display behaviours outside of breeding season) could be explained by a non-ovulatory cycle that was not detected via progesterone monitoring. Increased frequency of blow sampling, the addition of oestradiol measurements, or ultrasound examinations at key times to confirm or refute findings from blow sampling would aid in identifying reproductive events with greater certainty, reducing reliance on inferences. However, the rigorous validation of hormone measurements in blow, for these purposes, 
under these sampling conditions with these belugas (Richard, Robeck et al. 2017) lends confidence to the physiological interpretations made in this study.

Patterns of male-female behaviour were influenced by Fl's reproductive condition, with markedly more frequent associations and behavioural events occurring during Fl's breeding season. There did not appear to be a difference in female-male association patterns between Fl's inferred follicular phases, when she would be expected to be most receptive, and the remaining weeks of the breeding season. The uncertainty associated with identifying oestrous cycle stages in this study could account for this observation. However, if female receptivity was the only factor influencing this behaviour, even shorter periods of relatively high female-male association would be expected. Although this may be explained by the lack of additional receptive females for the males to interact with, there was no evidence of the males coercing the female to associate with them. Alternatively, the observed pattern of prolonged periods of more frequent and longer female-male associations would also provide the female with opportunity to evaluate potential mates, consistent with predictions based on ovulation mode.

Knowledge of Fl's breeding season allowed for the description of presumed courtship behaviours through their disproportionate occurrence during the breeding season. Courtship was characterised by visual displays predominantly performed by the males (genital present, melon shake, head nod and flutter). In particular, the strong correspondence of male-female genital presents with the breeding season, along with the high frequency of occurrence during that time, suggests a courtship function for this behaviour. The rarity of erections during male-female genital presents suggests a display function as opposed to attempted copulation. Whilst inferred to have occurred at least three times, copulation was not observed to confirm the courtship function of these display behaviours. Copulation is rarely observed in belugas in aquaria despite regular conceptions (Glabicky et al. 2010; Hill et al. 2015), which contrasts with other species of odontocetes in both aquaria and the wild, where copulation is commonly observed relative to sampling effort (Puente \& Dewsbury 1976; Orbach et al. 2019). A low copulation rate is consistent with predictions based on beluga reproductive physiology, necessitating 24-hour video monitoring to observe copulation and more definitively describe the function of these behaviours.

The prevalence of visual displays performed by the males towards Fl would provide potential mechanisms for pre-copulatory female mate choice. Although this sample was small, the observed courtship behaviours are consistent with the behavioural repertoire of belugas at several different aquaria and include behaviours not previously described in studies of socio-sexual behaviour (Glabicky et al. 2010; Hill et al. 2015; Hill et al. 2016). Visual courtship displays occurred at much higher rates than previously reported in other odontocetes, whilst tactile, aggressive/coercive or high-speed chase behaviours that characterise courtship in other odontocetes were rare or absent (Wells 1984; Scott et al. 2004; Muraco \& Kucjaz 2015; Orbach et al. 2019). The importance of behavioural displays would explain the apparent low investment in pre- or post-copulatory morphological traits in belugas relative to other cetaceans (Dines et al. 2015). Given the importance of vocal communication in this species (Castellote et al. 2019), future studies in aquaria should prioritise obtaining vocalisation data to more fully characterise courtship behaviour.

Whilst female-male association and courtship behaviour coincided with Fl's breeding season, there was a weaker association with measures of male reproductive physiology. The seasonal timing of presumed courtship behaviour (primarily March through May) was consistent with previous observations of male beluga reproductive seasonality and the timing of conceptions in aquaria (Robeck, Monfort et al. 2005; Richard, Schmitt et al. 2017). The more frequent occurrence of courtship whilst testosterone and testes size were declining contrasts with spinner dolphins (Stenella longirostris; Wells 1984) and finless porpoises (Neophocaena phocaenoides asiaeorientalis; Wu et al. 2010). Testosterone still likely played a role in regulating male behaviour, as both female-male association and courtship behaviour all but ceased for Ml after blow testosterone fell below the annual mean concentration. However, the low rates of female-male interaction whilst testosterone or testes size were increasing or at peak values suggest that signalling from the female indicating receptivity played an important role in eliciting courtship behaviour from the males.

One potential indicator of female receptivity is a change in the willingness to swim in close association with a male. As proposed by Hill et al. (2015), group swimming served an important function in beluga social interactions observed in this study. Female-male group swimming occurred almost exclusively during the breeding season and was concentrated primarily in the observation sessions that also contained male-female genital presents. Group swimming was not necessarily synchronous, as described in other species (Connor et al. 2006), and it appeared that either the male or the female could lead the direction and pace of swimming during a group swim. Swimming in this manner requires cooperation and could, therefore, be used to assess female mate choice, especially if group swimming is associated with courtship behaviours, as it was in this study. Although both males were frequently simultaneously observed in a 
group swim with F1, courtship behaviour during these triad interactions was almost exclusively between Ml and Fl. With both males available for interaction at the same time, this is perhaps indicative of Fl's choice to swim in closer association with M1 as opposed to M2 at those times. Whilst female-male interactions were typically initiated by males and terminated by females in this group, this pattern was weaker during the breeding season. This could indicate a change in the female's willingness to swim in close association with a male and receive courtship displays. This behaviour is likely affected by social grouping, but its potential function in mate choice merits further study.

Another potential indicator of female receptivity is the behavioural response to courtship behaviour. The slow, deliberate pace of the genital present, as well as the associated termination of active forward propulsion by the displaying male leaves a clear opportunity for the female recipient to respond in a way that either allows contact to occur or not, as well as where on the body that contact can occur. In this study, Fl was observed to variably alter her swim speed or body orientation in response to genital presents, resulting in greater receptivity towards $\mathrm{Ml}$ 's displays. Fl's variable responses are analogous to those described in other species of odontocetes (Orbach et al. 2015; Orbach et al. 2017). More extensive video monitoring that captures occurrences of copulation is needed to determine if these measures of receptivity during courtship are predictors of mate choice.

If pre-copulatory female mate choice is an important strategy for belugas, then behavioural traits would be expected to vary among adult males, which would precipitate the observed variation in responses from the female. Even with the limited amount of observations and the small number of belugas studied, individual variation has been documented in male courtship displays. Neither male performed genital presents at the water's surface with a lateral preference as described in the ethogram created by Hill et al. (2015). Although Fl spent more total time associating and engaged in more courtship behaviours with M2, she preferentially swam with Ml and was more receptive to Ml's genital present displays during the periods of presumed receptivity. As a proven sire, Ml may have been better able to detect Fl's receptiveness during these periods, and therefore concentrated displays during this time. However, the absence of coercive behaviour by the males suggests a preference for Ml when Fl was inferred to be most receptive. Fl's preference for $\mathrm{Ml}$ during key times of the oestrous cycle may have occurred because M2 was likely immature during the study period. Whilst M2 had adult levels of testosterone, his testes were approximately half the volume of mature belugas in aquaria and the wild (Brodie 1971; Richard, Schmitt et al. 2017). Most of the interactions between M2 and Fl occurred later in the breeding season and outside of inferred follicular phases. In ungulates, juvenile males may display similarly ineffective courtship behaviour (Milner et al. 2007). Fl's choice to interact with M2 when she was presumably less receptive is less clearly explained, although socio-sexual interactions have been observed between adult females and juvenile males in previous studies of belugas (Glabicky et al. 2010; Hill et al. 2015). Studies of social groups with multiple mature males are required to better understand the influence of variation of male courtship displays on female behaviour.

Mating systems with pre-copulatory female mate choice are often associated with sexually selected male traits (Clutton-Brock \& McAuliffe 2009), which is consistent with the sexual dimorphism observed in belugas. The display behaviours performed by male belugas during courtship in this study seemingly emphasise sexually dimorphic traits, including body size and shape (Kleinenberg et al. 1969), melon size and shape (Kleinenberg et al. 1969), curling of the pectoral flippers (Brodie 1989) and abdominal fat pads (Werth \& Ford 2012). In addition, the distinctive white colouration of belugas, present in males only after the attainment of sexual maturity (Kleinenberg et al. 1969; Burns \& Seaman 1988), would facilitate the visibility of these displays in the low-light conditions of the Arctic during the breeding season. Studying more multi-male social groupings in aquaria would lead to a better understanding of preferred behavioural and morphological traits, and therefore the potential for sexual selection to occur.

Sexual dimorphism can also be associated with malemale competition for access to mates, but there was little evidence that this was important in this social group. Association and genital presents between the males occurred at similar rates throughout the year, and Ml would frequently tolerate the presence of M2 whilst interacting with F1. Low rates of male-male aggression suggest that male-female interactions did not function as mate guarding behaviour as described in other cetaceans (Schaeff 2007), perhaps because mate guarding is less important in securing paternity among species with induced ovulation (Soulsbury 2010). M2's maturity status may explain the low rate of male-male aggression, although M2's apparent observation of Ml's courtship behaviour towards F1 also suggests that M2 was learning to engage in courtship. Social structure during the breeding season in the wild is largely unknown, but in most cases, a female would become pregnant whilst still accompanied by a nursing calf (Brodie 1971). This implies 
that at least young calves would have an opportunity to observe courtship and mating. Ontogenetic changes in male socio-sexual behaviour have been documented in one aquarium population (Lilley et al. 2020), but the role of learning in that development is unknown. Comparing various aquarium populations would reveal if males that are housed together show similar behaviour to each other that is different from other social groupings.

Whilst the sample size in this study is prohibitively small to draw broad conclusions, the results of this study are consistent with predictions resulting from the growing understanding of beluga reproductive physiology, establishing several paths for future research on beluga reproductive behaviour. Continued research in this area is important because if females select mates during prolonged courtship periods, then there are critical implications for wild beluga management. In smaller populations, female belugas may have reduced opportunities for choice due to difficulty in finding mates or the inability to sample enough males for preferred phenotypes before selecting a mate (Quader 2005). This is problematic because limiting opportunities for female mate choice has negatively impacted reproductive rate across a variety of taxa (Møller \& Legendre 2001; Candolin 2019). In belugas, the effects of small population sizes on mate choice may be exacerbated by anthropogenic factors. Breeding behaviour may be affected by sea-ice loss, which disrupts migration patterns (O'Corry-Crowe et al. 2016), widens distributions (Heide-Jørgensen et al. 2010) and leads to an increase in the threat of killer whale predation (Higdon \& Ferguson 2009). Anthropogenic noise can mask vocal signalling that may be important in locating or selecting mates (Castellote et al. 2019; Mitoyen et al. 2019). Selective subsistence harvests that target larger adult males (Harwood et al. 2014; Hobbs et al. 2015) could reduce the abundance of preferred males. These factors could combine to disrupt beluga social structures and mating systems.

These potential disruptions have previously been considered as possible explanations for the failure of small beluga populations to recover (Wade et al. 2012; Hobbs et al. 2015), and this study has provided specific behavioural mechanisms that should be further investigated to explore this possibility. As behavioural observations of belugas with known reproductive status during the breeding season are not feasible in the wild, determining the sex ratio, age structure and kinship within a population is necessary to determine the number of potential sires available and the proportion of potential sires that are reproducing. Advancing unmanned aerial vehicle sampling methodologies (Centelleghe et al. 2020) could allow blow sampling for molecular purposes (Richard, Schultz et al. 2017) to support these efforts, especially for young animals typically excluded from biopsy sampling (Citta et al. 2018). Applying this study's approach of simultaneously monitoring behaviour and physiology to larger and more diverse social groups, made possible through the application of minimally invasive blow sampling, will also be an important component of these efforts. The year-round underwater visibility of belugas in aquaria is critical, as courtship behaviour frequently occurred several feet below the surface where wild belugas are rarely observable, especially during the breeding season. Knowledge gained in aquaria can be used to refine hypotheses regarding mating strategies that could help explain why beluga populations are not recovering at expected rates.

\section{Conclusions}

Minimally invasive assessments of reproductive physiology were used to contextualise behavioural observations in a group of belugas in professionally managed care. Despite a small sample size, several observed patterns were consistent with the limited knowledge of social behaviour in wild belugas. Whilst broad conclusions are limited by the group composition and sample size of this group of belugas, there were several findings that are consistent with predictions based on the induced mode of ovulation in this species. Observations suggest that pre-copulatory female mate choice was relatively important in this group; female-male interactions during the period of receptivity for the study female were characterised by relatively long interactions, frequent display behaviours, low copulation rates and infrequent and mild aggression. Potential behavioural mechanisms for female mate choice include selecting individual males to swim in close association with, preferentially initiating or terminating coordinated interactions with individual males and responding variably to display behaviours. Additional studies of behaviour and physiology in aquaria and the demographics and kinship of wild populations will provide the complementary information required to validate these findings. If these mating strategies are important for wild belugas, then perhaps reduced opportunities for mate choice due to various environmental and anthropogenic factors could be limiting reproductive rate and population recovery, especially in small populations.

\section{Acknowledgements}

This study would not have been possible without the assistance of the beluga trainers and veterinarians at Mystic Aquarium, especially Kristine Magao, Lindsey 
Nelson, Kate McElroy, Kathryn Justice, Allyson McNaughton and Allison Tuttle. Behavioural observations were made possible through the contributions of Daniel Catizone, Noël Vezzi, Anthony Cammarano and Kathleen Leach. Special thanks to research assistants Crysania Brady and Renee Bakker for their assistance in all aspects of the project, and to Paul Anderson for providing valuable guidance and suggestions. We thank the critical reading of two anonymous reviewers who helped clarify this manuscript. This constitutes scientific contribution no. 317 from the Sea Research Foundation, Inc.

\section{Disclosure statement}

The authors report no conflict of interest.

\section{Funding}

This material is based upon work supported by the National Science Foundation Graduate Research Fellowship awarded to JTR under grant no. 1244657. Funding for this project was provided by the Sea Research Foundation, Inc. d/b/a Mystic Aquarium and through the University of Rhode Island's Enhancement of Graduate Research Award programme.

\section{References}

Bartsh S.S., Johnston S.D. \& Siniff D.B. 1992. Territorial behavior and breeding frequency of male Weddell seals (Leptonychotes weddelli) in relation to age, size, and concentrations of serum testosterone and cortisol. Canadian Journal of Zoology 70, 680-692, doi: 10.1139/z92-102.

Brodie P.F. 1971. A reconsideration of aspects of growth, reproduction and behavior of the white whale (Delphinapterus leucas) with reference to the Cumberland Sound, Baffin Island population. Journal Fisheries Research Board of Canada 28, 1309-1318, doi: 10.1139/f71-198.

Brodie P.F. 1989. The white whale Delphinapterus leucas (Pallas, 1776). In S.H. Ridgway \& S.R. Harrison (eds.): Handbook of marine mammals. Vol. 4: river dolphins and the larger toothed whales. Pp. 119-144. New York: Academic Press.

Burgess E.A., Lanyon J.M. \& Keeley T. 2012. Testosterone and tusks: maturation and seasonal reproductive patterns of live, free-ranging male dugongs (Dugong dugon) in a subtropical population. Reproduction 143, 683-697, doi: 10.1530/REP-11-0434.

Burns J.J. \& Seaman G.A. 1988. Investigations of Belukha whales in coastal waters of western and Northern Alaska. II. Biology and ecology. Final report. Outer Continental Shelf Environmental Assessment Program. Fairbanks, AK: Alaska Department of Fish \& Game.
Cairns S.J. \& Schwager S.J. 1987. A comparison of association indices. Animal Behaviour 35, 1454-1469, doi: 10.1016/S0003-3472(87)80018-0.

Candolin U. 2019. Mate choice in a changing world. Biological Reviews 94, 1246-1260, doi: 10.1111/brv.12501.

Castellote M., Thayre B., Mahoney M., Mondragon J., Lammers M.O. \& Small R.J. 2019. Anthropogenic noise and the endangered Cook Inlet beluga whale, Delphinapterus leucas: acoustic considerations for management. Marine Fisheries Review 80(3), 63-88, doi: 10.7755/ MFR.80.3.3.

Centelleghe C., Carraro L., Gonzalvo J., Rosso M., Esposti E., Gili C., Bonato M., Pedrotti D., Cardazzo B., Povinelli M. \& Mazzariol S. 2020. The use of unmanned aerial vehicles (UAVs) to sample the blow microbiome of small cetaceans. PLoS One 15, e0235537, doi: 10.1371/journal. pone. 0235537.

Citta J.J., O'Corry-Crowe G., Quakenbush L.T., Bryan A.L., Ferrer T., Olson M.J., Hobbs R.C. \& Potgieter B. 2018. Assessing the abundance of Bristol Bay belugas with genetic mark-recapture methods. Marine Mammal Science 34, 666-686, doi: 10.1111/mms.12472.

Clutton-Brock T. \& McAuliffe K. 2009. Female mate choice in mammals. The Quarterly Review of Biology 84, 3-27, doi: 10.1086/596461.

Connor R.C., Smolker R. \& Bejder L. 2006. Synchrony, social behaviour and alliance affiliation in Indian Ocean bottlenose dolphins, Tursiops aduncus. Animal Behaviour 72, 1371-1378, doi: 10.1016/j.anbehav.2006.03.014.

Dines J.P., Mesnick S.L., Ralls K., May-Collado L., Agnarsson I. \& Dean M.D. 2015. A trade-off between precopulatory and postcopulatory trait investment in male cetaceans. Evolution 69, 1560-1572, doi: 10.1111/evo.12676.

DiPaola S., Akai C. \& Kraus B. 2007. Experiencing belugas: action selection for an interactive aquarium exhibit. Adaptive Behavior 15, 99-113, doi: 10.1177/1059712306076251.

Glabicky N., DuBrava A. \& Noonan M. 2010. Social-sexual behavior seasonality in captive beluga whales (Delphinapterus leucas). Polar Biology 33, 1145-1147, doi: 10.1007/s00300-010-0790-3.

Hänninen L. \& Pastell M. 2009. CowLog: open-source software for coding behaviors from digital video. Behavior Research Methods 41, 472-476, doi: 10.3758/BRM.41.2.472.

Harwood L.A., Kingsley M.C.S. \& Smith T.G. 2014. An emerging pattern of declining growth rates in belugas of the Beaufort Sea: 1989-2008. Arctic 67, 483-492, doi: $10.14430 /$ arctic4423.

Heide-Jørgensen M.P., Laidre K.L., Borchers D., Marques T.A., Stern H. \& Simon M. 2010. The effect of sea-ice loss on beluga whales (Delphinapterus leucas) in west Greenland. Polar Research 29, 198-208, doi: $10.1111 / \mathrm{j} .1751-8369.2009 .00142 . x$.

Higdon J.W. \& Ferguson S.H. 2009. Loss of Arctic sea ice causing punctuated change in sightings of killer whales (Orcinus orca) over the past century. Ecological Applications 19, 1365-1375, doi: 10.1890/07-1941.1.

Hill H.M., Alvarez C.J., Dietrich S. \& Lacy K. 2016. Preliminary findings in Beluga (Delphinapterus leucas) 
tactile interactions. Aquatic Mammals 42, 277-291, doi: 10.1578/AM.42.3.2016.277.

Hill H.M., de Oliveira Silva-Gruber D.G. \& Noonan M. 2018. Sex-specific social affiliation in captive beluga whales (Delphinapterus leucas). Aquatic Mammals 44, 250-255, doi: 10.1578/AM.44.3.2018.250.

Hill H.M., Dietrich S., Yeater D., McKinnon M., Miller M., Aibel S. \& Dove A. 2015. Developing a catalog of socio-sexual behaviors of beluga whales (Delphinapterus leucas) in the care of humans. Animal Behaviour and Cognition 2, 105-123, doi: 10.12966/abc.05.01.2015.

Hobbs R.C., Wade P.R. \& Shelden K.E.W. 2015. Viability of a small, geographically-isolated population of beluga whales, Delphinapterus leucas: effects of hunting, predation, and mortality events in Cook Inlet, Alaska. Marine Fisheries Review 77, 59-88, doi: 10.7755/MFR.77.2.4.

Høier R. \& Heide-Jørgensen M.P. 1994. Steroid hormones and prolactin in white whales (Delphinapterus leucas) from west Greenland. Bioscience 39, 227-238.

Iossa G., Soulsbury C.D., Baker P.J. \& Harris S. 2008. Sperm competition and the evolution of testes size in terrestrial mammalian carnivores. Functional Ecology 22, 655-662, doi: $10.1111 / \mathrm{j} .1365-2435.2008 .01409 . x$.

Katsumata E., Furuta C., Katsumata H., Watanabe G. \& Taya K. 2006. Basal body temperature method for detecting ovarian cycle in the captive beluga (Delphinapterus leucas). Journal of Reproduction and Development 52, 59-63, doi: $10.1262 /$ jrd.17066.

Kaufman A.B. \& Rosenthal R. 2009. Can you believe my eyes? The importance of interobserver reliability statistics in observations of animal behaviour. Animal Behaviour 78, 1487-1491, doi: 10.1016/j.anbehav.2009.09.014.

Kelley T.C., Stewart R.E.A., Yurkowski D.J., Ryan A. \& Ferguson S.H. 2014. Mating ecology of beluga (Delphinapterus leucas) and narwhal (Monodon monoceros) as estimated by reproductive tract metrics. Marine Mammal Science 31, 479-500, doi: 10.1111/mms.12165.

Kleinenberg S.E., Yablokov A.V., Bel'kovich B.M. \& Tarasevich M.N. 1969. Beluga (Delphinapterus leucas): investigation of the species. Jerusalem: Israel Program for Scientific Translations.

Lacey E.A., Wieczorek J.R. \& Tucker P.K. 1997. Male mating behaviour and patterns of sperm precedence in Arctic ground squirrels. Animal Behaviour 53, 767-779, doi: 10.1006/anbe.1996.0342.

Lilley M.K., Ham J.R. \& Hill H.M. 2020. The development of socio-sexual behaviour in belugas (Delphinapterus leucas) under human care. Behavioural Processes 171, 104025, doi: 10.1016/j.beproc.2019.104025.

Loseto L.L., Richard P., Stern G.A., Orr J. \& Ferguson S.H. 2006. Segregation of Beaufort Sea beluga whales during the open-water season. Canadian Journal of Zoology 84, 1743-1751, doi: 10.1139/z06-160.

Mann J. 2006. Establishing trust: socio-sexual behavior and the development of male-male bonds among Indian Ocean bottlenose dolphins. In V. Sommer \& P.L. Vasey (eds.): Homosexual behavior in animals: an evolutionary perspective. Pp. 107-130. New York: Cambridge University Press.
Martin P. \& Bateson P. 2007. Measuring behavior: an introductory guide. 3rd edn. Cambridge: Cambridge University Press.

Michaud R. 2005. Sociality and ecology of the odontocetes. In K.E. Ruckstuhl \& P. Neuhaus (eds.): Sexual segregation in vertebrates: ecology of the two sexes. Pp. 303-326. New York: Cambridge University Press.

Milner J.M., Nilsen E.B. \& Andreassen H.P. 2007. Demographic side effects of selective hunting in ungulates and carnivores. Conservation Biology 21, 36-47, doi: 10.1111/j.1523-1739.2006.00591.x.

Mitoyen C., Quigley C. \& Fusani L. 2019. Evolution and function of multimodal courtship displays. Ethology 125, 503-515, doi: 10.1111/eth.12882.

Møller A.P. \& Legendre S. 2001. Allee effect, sexual selection and demographic stochasticity. Oikos 92, 27-34, doi: 10.1034/j.1600-0706.2001.920104.x.

Muraco H. \& Kuczaj S.A. 2015. Conceptive estrus behavior in three bottlenose dolphins (Tursiops truncatus). Animal Behavior and Cognition 2, 30-48, doi: 10.12966/ abc.02.03.2015.

Neimanis A.S., Read A.J., Foster R.A. \& Gaskin D.E. 2000. Seasonal regression in testicular size and histology in harbor porpoises (Phocoena phocoena) from the Bay of Fundy and Gulf of Maine. London Journal of Zoology 250, 221-229, doi: 10.1111/j.1469-7998.2000.tb01072.x.

O’Brien J.K., Steinman K.J., Schmitt T. \& Robeck T.R. 2008. Semen collection, characterization and artificial insemination in the beluga (Delphinapterus leucas) using liquid-stored spermatozoa. Reproduction, Fertility and Development 20, 770-783, doi: 10.1071/RD08031.

O'Corry-Crowe G.M., Mahoney A.R., Suydam R., Quakenbush L., Whiting A., Lowry L. \& Harwood L. 2016. Genetic profiling links changing sea-ice to shifting beluga whale migration patterns. Biology Letters 12, 20160404, doi: 10.1098/rsbl.2016.0404.

O'Corry-Crowe G.M., Suydam R., Quakenbush L., Smith T.G., Lydersen C., Kovacs K.M., Orr J., Harwood L., Litovka D. \& Ferrer T. 2020. Group structure and kinship in beluga whale societies. Scientific Reports 10, 11462, doi: 10.1038/s41598-020-67314-w.

O'Corry-Crowe G.M., Suydam R.S., Rosenberg A., Frost K.J. \& Dizon A.E. 1997. Phylogeography, population structure and dispersal patterns of the beluga whale Delphinapterus leucas in the western Nearctic revealed by mitochondrial DNA. Molecular Ecology 6, 955-970, doi: 10.1046/j.1365-294X.1997.00267.x.

Orbach D.N., Kelly D.A., Solano M. \& Brennan P.L.R. 2017. Genital interaction during simulated copulation among marine mammals. Proceedings of the Royal Society B 284, article no. 20171265, doi: 10.1098/rspb.2017.1265.

Orbach D.N., Packard J.M., Keener W., Ziltener A. \& Würsig B. 2019. Testes size, vaginal complexity, and behavior in toothed whales (odontocetes): arms race or tradeoff model for dusky dolphins (Lagenorhynchus obscurus), harbor porpoises (Phocoena phocoena), and bottlenose dolphins (Tursiops spp.)? Journal of Comparative Psychology 133, article no. 359, doi: 10.1037/com0000162. 
Orbach D.N., Packard J.M., Kirchner T. \& Würsig B. 2015. Evasive behaviours of female dusky dolphins (Lagenorhynchus obscurus) during exploitative scramble competition. Behaviour 152, 1953-1977, doi: 10.1163/1568539X-00003310.

Puente A.E. \& Dewsbury D.A. 1976. Courtship and copulatory behavior of bottlenose dolphins (Tursiops truncatus). Cetology 21, 1-9.

Quader S. 2005. Mate choice and its implications for conservation and management. Current Science 89, 1220-1229.

$\mathrm{R}$ Core Team 2020. $R$ : a language and environment for statistical computing. Vienna: R Foundation for Statistical Computing.

Richard J.T., Robeck T.R., Osborn S.D., Naples L., McDermott A., LaForge R., Romano T.A. \& Sartini B.L. 2017. Testosterone and progesterone concentrations in blow samples are biologically relevant in belugas (Delphinapterus leucas). General and Comparative Endocrinology 246, 183-193, doi: 10.1016/j.ygcen.2016.12.006.

Richard J.T., Schmitt T., Haulena M., Vezzi N., Dunn J.L., Romano T.A. \& Sartini B.L. 2017. Seasonal variation in testes size and density detected in belugas (Delphinapterus leucas) using ultrasonography. Journal of Mammalogy 98, 874-884, doi: 10.1093/jmammal/gyx032.

Richard J.T., Schultz K., Goertz C., Hobbs R., Romano T.A. \& Sartini B.L. 2017. Assessing the quantity and downstream performance of DNA isolated from beluga (Delphinapterus leucas) blow samples. Aquatic Mammals 43, 398-408, doi: 10.1578/AM.43.4.2017.398.

Robeck T.R., Monfort S.L., Calle P.P., Dunn J.L., Jensen E., Boehm J.R., Young S. \& Clark S.T. 2005. Reproduction, growth and development in captive beluga (Delphinapterus leucas). Zoo Biology 24, 29-49, doi: 10.1002/zoo.20037.

Robeck T.R., Schneyer A.L., McBain J.F., Dalton L.M., Walsh M.T., Czekala N.M. \& Kraemer D.C. 1993. Analysis of urinary immunoreactive steroid metabolites and gonadotropins for characterization of the estrous cycle, breeding period, and seasonal estrous activity of captive killer whales (Orcinus orca). Zoo Biology 12, 173-187, doi: 10.1002/ zoo.1430120204.

Robeck T.R., Steinman K.J., Yoshioka M., Jensen E., O'Brien J.K., Katsumata E., Gili C., McBain J.F., Sweeney J. \& Monfort S.L. 2005. Estrous cycle characterization and artificial insemination using frozen-thawed spermatozoa in the bottlenose dolphin (Tursiops truncatus). Reproduction 129, 659-674, doi: 10.1530/rep.1.00516.

Schaeff C.M. 2007. Courtship and mating behavior. In D.L. Miller (ed.): Reproductive biology and phylogeny of Cetacea: whales, dolphins, and porpoises. Pp. 349-370. Enfield, NH: Science Publishers.

Schroeder J.P. \& Keller K.V. 1989. Seasonality of serum testosterone levels and sperm density in Tursiops truncatus. The Journal of Experimental Zoology 249, 316-321, doi: 10.1002/ jez.1402490310.

Scott E.M., Mann J., Watson-Capps J.J., Sargeant B.L. \& Connor R.C. 2004. Aggression in bottlenose dolphins: evidence for sexual coercion, male-male competition, and female tolerance through analysis of tooth-rake marks and behaviour. Behaviour 142, 21-44, doi: 10.1163/1568539053627712.

Soulsbury C.D. 2010. Ovulation mode modifies paternity monopolization in mammals. Biology Letters 6, 39-41, doi: $10.1098 / \mathrm{rsbl} .2009 .0703$

Soulsbury C.D. \& Iossa G. 2010. The impact of ovulation mode on sperm quantity and quality in mammals. Evolutionary Ecology 24, 879-889, doi: 10.1007/s10682-009-9344-y.

Steinman K.J., O'Brien J.K., Monfort S.L. \& Robeck T.R. 2012. Characterization of the estrous cycle in female beluga (Delphinapterus leucas) using urinary endocrine monitoring and transabdominal ultrasound: evidence of facultative induced ovulation. General and Comparative Endocrinology 175, 389-397, doi: 10.1016/j.ygcen.2011.11.008.

Wade P.R., Reeves R.R. \& Mesnick S.L. 2012. Social and behavioral factors in cetacean responses to overexploitation: are odontocetes less "resilient" than mysticetes? Journal of Marine Biology 2012(2), article no. 567276, doi: $10.1155 / 2012 / 567276$.

Wells R.S. 1984. Reproductive behavior and hormonal correlates in Hawaiian spinner dolphins, Stenella longirostris. Reports to the International Whaling Commission Special Issue 6, 465-472.

Werth A.J. \& Ford T.J. Jr. 2012. Abdominal fat pads act as control surfaces in lieu of dorsal fins in the beluga (Delphinapterus). Marine Mammal Science 28, 516-527, doi: 10.1111/j.1748-7692.2012.00567.x.

Wingfield J.C., Hegner R.E., Dufty A.M. Jr. \& Ball G.F. 1990. The "challenge hypothesis": theoretical implications for patterns of testosterone secretion, mating systems, and breeding strategies. The American Naturalist 136, 829-846, doi: $10.1086 / 285134$.

Wu H., Hao Y., Yu X., Xian Y., Zhao Q., Chen D., Kuang X., Kou Z., Feng K., Gong W. \& Wang D. 2010. Variation in sexual behaviors in a group of captive male Yangtze finless porpoises (Neophocaena phocaenoides asiaeorientalis): motivated by physiological changes? Theriorgenology 74 , 1467-1475, doi: 10.1016/j.theriogenology.2010.06.018. 